\title{
A case of maxillary sarcoma in a chimpanzee (Pan troglodytes).
}

\section{AUTHOR(S):}

Fujisawa, M; Udono, T; Nogami, E; Hirosawa, M; Morimura, N; Saito, A; Seres, M; ... Hirata, S; Tsuruyama, T; Matsubayashi, $\mathrm{K}$

\section{CITATION:}

Fujisawa, M ...[et al]. A case of maxillary sarcoma in a chimpanzee (Pan troglodytes).. Journal of medical primatology 2014, 43(2): 111-114

\section{ISSUE DATE:}

2014-04

URL:

http://hdl.handle.net/2433/199614

\section{RIGHT:}

This is the peer reviewed version of the following article: Fujisawa, M., Udono, T., Nogami, E., Hirosawa, M., Morimura, N., Saito, A., Seres, M., Teramoto, M., Nagano, K., Mori, Y., Uesaka, H., Nasu, K., Tomonaga, M., Idani, G., Hirata, S.,

Tsuruyama, T. and Matsubayashi, K. (2014), A case of maxillary sarcoma in a chimpanzee (Pan troglodytes). Journal of Medical Primatology, 43: 111-114, which has been published in final form at http://dx.doi.org/10.1111/jmp.12086. This article may be used for non-commercial purposes in accordance with Wiley Terms and Conditions for Self-Archiving.; This is not the published version. Please cite only the published version.; この論文は出版社版でありません。引用の際 には出版社版をご確認ご利用ください。 
1 A case of maxillary sarcoma in a chimpanzee (Pan troglodytes)

2 Michiko Fujisawa $^{1,2}$, Toshifumi Udono ${ }^{1}$, Etsuko Nogami ${ }^{1}$, Mari Hirosawa ${ }^{1}$, Naruki Morimura ${ }^{1}$,

3 Aya Saito ${ }^{1}$, Michael Seres ${ }^{3}$, Migaku Teramoto ${ }^{1}$, Kunitoshi Nagano ${ }^{1}$, Yusuke Mori ${ }^{1}$, Hirosuke

4 Uesaka $^{1}$, Kazuyo Nasu${ }^{1}$, Masaki Tomonaga ${ }^{3}$, Gen’ichi Idani ${ }^{1}$, Satoshi Hirata ${ }^{3}$, Tatsuaki

$5 \quad$ Tsuruyama ${ }^{4}, K_{0 z o}$ Matsubayashi ${ }^{2}$

6

7 1. Kumamoto Sanctuary, Wildlife Research Center, Kyoto University, Uki, Kumamoto,

$8 \quad$ Japan

9 2. Center for Southeast Asian Studies, Kyoto University, Kyoto, Kyoto, Japan

3. Primate Research Institute, Kyoto University, Inuyama, Aichi, Japan

4. Department of Diagnostic Pathology, Kyoto University Hospital, Kyoto, Kyoto, Japan

13 Acknowledgments of funding

14 This study was financially supported by MEXT (20002001, 20040001, 22659141) and WISH Grant and

15 Human Evolution Grant to the Primate Research Institute, Kyoto University.

17 Corresponding author: Michiko Fujisawa

18 Center for Southeast Asian Studies, Kyoto University 
20 Tel: 075-753-7302,

21 Fax: 075-753-7350,

22 E-mail: mfujisaw@cseas.kyoto-u.ac.jp

24 Running Title

25 A case of maxillary sarcoma in a chimpanzee.

26

27

Total numbers of figure

28

2

29

$30 \quad$ Key Words

31 ape, malignant neoplasm, aging, care

34 Abstract

35 Oral malignancy is rare in chimpanzees. A 34-year-old female chimpanzee (Pan troglodytes) at Kumamoto

36 Sanctuary, Japan had had developed it. Treatment is technically difficult for chimpanzees while malignant

37 neoplasm is seemingly rising in captive populations. Widespread expert discussion, guidelines for

38 treatment, especially for great apes in terminal stages is urgently needed. 
Case Report

Genetically chimpanzees are the closest living relatives of human. We were diverged almost 7 millions

years ago, and the changes in disease conditions could have occurred in conjunction with evolutionary

changes. As our life expectancies increased, the later-onset diseases such as malignant neoplasm,

arteriosclerotic diseases, and dementia have also increased, thus, becoming a serious issue. These diseases

are dependent on the lifestyle and aging; they could be referred to as age-dependent diseases.

In contrast, very little is known about the nature of age-dependent diseases in chimpanzees. The

chimpanzees. For example, malignancy is extremely rare in chimpanzees [4]. Previous studies have shown

only few examples of such diseases in chimpanzees $[2,5]$.

This is the first report of oral sarcoma in a chimpanzee. The case occurred in an estimated 34-year-old between 1979 and 1987. Persistent HCV infection was observed without other specific notations. 
Figure 2 shows histopathological image of the lesion. Abnormal undifferentiated cells including

spindle cells and adipose-like cells proliferated papillary or focally. Increased N/C ratio and multiple images of mitosis showed this tumor was highly malignant. By immunohistological stain, vimantin was positive, cytokeratine was partially slightly positive. On X-ray examination maxilla invasion was identified, however, no pulmonary metastasis could be observed. Cervical lymph nodes were not swollen. chemotherapy. In this case, because extensive resection was required, the reconstruction of the oral cavity must be considered. Surgical resection and radiation could not be options due to technical difficulties. results. It was also difficult to give her injection due to risking anesthesia on a daily basis. A conservative palliative treatment was chosen instead during the remaining progression of the disease. still achieved by altering the texture of food. A timetable was created incorporating contact time with other chimpanzees, with staffs, and time spent alone. Gradually, the time spent being recumbent increased, however, she would still rise to interact with staff. Breathing difficulty appeared except when lying on her right side. On August 15, she had eventually attempted to roll over and reached with her arms and legs out to staff. She died at 9:30 am on August 17. Euthanasia was debated during the course, but was not performed because she was still able to ingest food and did not appear to be in great distress. 
her maxilla. The mass had protruded into the oral cavity, and it was largely necrotic and ulcerated but the

tumor had not yet progressed into the orbital cavity. Despite the tumor extended almost to cover the entire

palate it did not reach the pharynx. The mandible and cervical lymph nodes were largely swollen and the

right cervical lymph nodes entwined the carotid artery. Multiple metastatic lesions were identified in

81 lymph nodes of the pulmonary hilum and of posterior mediastinum, in lungs, and in diaphragm. The right lung showed poor aeration with the lower lung atelectasis. No pleural effusion was observed. No intraperitoneal spread was detected.

Pathological diagnosis: (1) maxillary sarcoma with multiple metastases, (2) respiratory failure due to metastases.

There are very few reports of malignant tumors in chimpanzees. Till recently, a number of hypotheses have been raised, including claims that malignant tumors are simply remain undiagnosed [5] or that because apoptosis suppression difference between human and chimpanzees, there is a known relationship between suppression of apoptosis and increased risk of the onset of malignancy [3][12]. Recent studies also have shown multiple genetic differences associated with malignancies [1, 8, 14, 15]. From these

91 findings, it is now understood that currently, there are very few identified genetic predispositions for malignant neoplasm in chimpanzees.

93 The ratio that of chimpanzees actually reaches an advanced age is low [9]. Although the frequency of

94 occurrence of malignancy because of gene restoration anomalies increases with aging, the frequency of 
96 the minimal number of age-related diseases that are observed in chimpanzees.

The case subject had persistent HCV infection. In humans, oral squamous-cell carcinoma is considered

as a complication of HCV infection [7, 10, 11, 13]. Chimpanzees with a history of being utilized in

hepatitis research are numerous in Japan and in several countries, including USA. Although cases of

hepatic carcinoma have been reported, thus far there have been no reports of oral malignancy.

As outlined above, the possibility is that HCV infection is partially responsible for the oral sarcoma.

Since the subject was not young, the potential for gene restoration mistakes to occur at a higher rate along

with advancement in age must also be taken into consideration.

appear. The subject was able to live out the remainder of her life in relative comfort during the terminal

\section{ACKNOWLEDGMENTS}

113 We thank Drs Yasunori Sumi and Zenzo Isogai of National Center for Geriatrics and

114 Gerontology Hospital for providing valuable suggestion on treating malignanct tumor in oral 
115 cavity and skin. This study was financially supported by the following grants: MEXT

116 20002001, 20040001, 22659141, and WISH Grant and Human Evolution Grant to the Primate Research

117 Institute, Kyoto University.

118

119 References

120

1) Ahmed J, Günther S, Möller F, Preissner R. A structural genomics approach to the regulation of apoptosis: chimp vs. human. Genome Inform 2007; 18: 22-34.

122

2) Amyx HL, Salazar AM, Newsome DA, Gibbs CJ Jr, Gajdusek DC: Nasopharyngeal carcinoma with intracranial extension in a chimpanzee. J Am Vet Med Assoc 1982; 181: 1425-1426.

3) Arora G, Polavarapu N, McDonald JF. Did natural selection for increased cognitive ability in humans lead to an elevated risk of cancer? Med Hypotheses 2009; 73: 453-456.

4) Bailey J: An examination of chimpanzee use in human cancer research. Alter Lab Anim 2009; 37: 399-416.

5) Brown SL, Anderson DC, Edward J. Dick Jr., Rodolfo G-M, AnaPatricia G, Gene BH. Neoplasia in the Chimpanzee. (Pan spp.)J Med Primatol. 2009; 38: 137-144.

6) Carrozzo M. Oral diseases associated with hepatitis $C$ virus infection. Part 1: sialadenitis and salivary glands lymphoma. Oral Dis 2008; 14: 123-130. 
134 8) Calarco JA, Xing Y, Cáceres M, Clarco JP, Xiao X, Pan Q, Lee C, Preuss TM, Blencowe BJ. Global

135 analysis of alternative splicing differences between humans and chimpanzees. Genes dev 2007; 21:

136 2963-2975.

137

9) Finch CE. Evolution of the human lifespan and disease of aging: role of infection, inflammation, and nutrition. Proc Natl Acad Sci 2010; 107: 1718-1724.

10) Gandolfo S, Richiardi L, Carrozzo M, Broccoletti R, Carbone M, Pagano M, Vestita C, Rosso S, Merletti F. Risk of oral squamous cell carcinoma in 402 patients with oral lichen planus: a follow-up study in an Italian population. Oral Oncol 2004; 40: 77-83.

11) Grossmann SM, Teixeira R, de Aguiar MC, de Moura MD, do Carmo MA. Oral mucosal conditions in chronic hepatitis C Brazilian patients: a cross-sectional study. J Public Health Dent 2009; 69: 168-175.

12) Lowe SW, Lin AW. Apoptosis in cancer. Carcinogenesis 2000; 21: 485-495.

13) Nagao Y, Sata M, Noguchi S, Seno’o T, Kinoshita M, Kameyama T, Ueno T: Detection of hepatitis C virus RNA in oral lichen planus and oral cancer tissues. J Oral Pathol Med 2000; 29: 259-266.

14) Wallace DC, Brown MD, Lott MT. Mitochondrial DNA variation in human evolution and disease.

15) Wallace DC. A mitochondrial paradigm of metabolic and degenerative diseases, aging, and cancer: A 


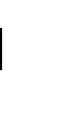

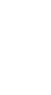

红

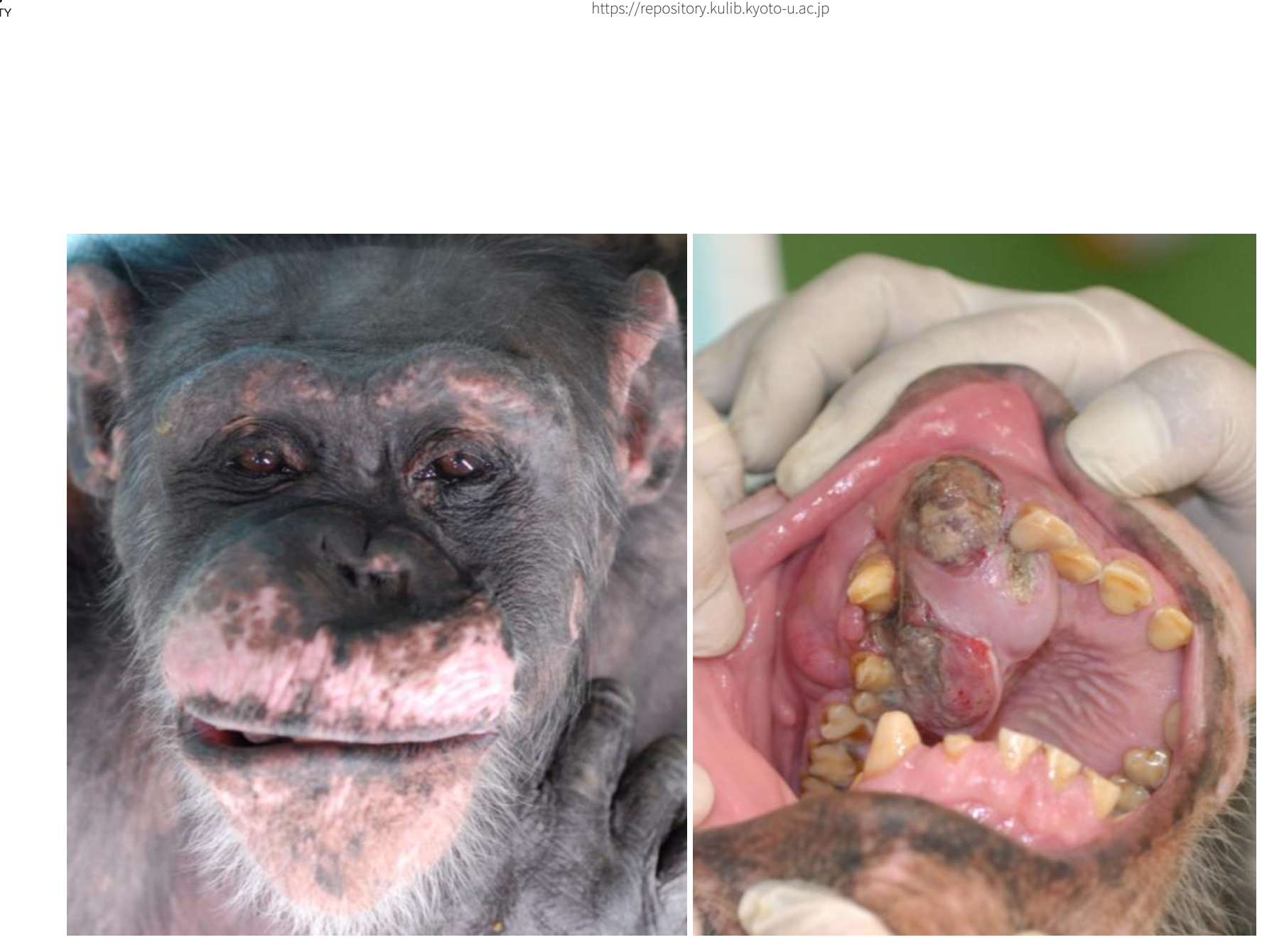

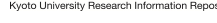

\section{Figure 1}

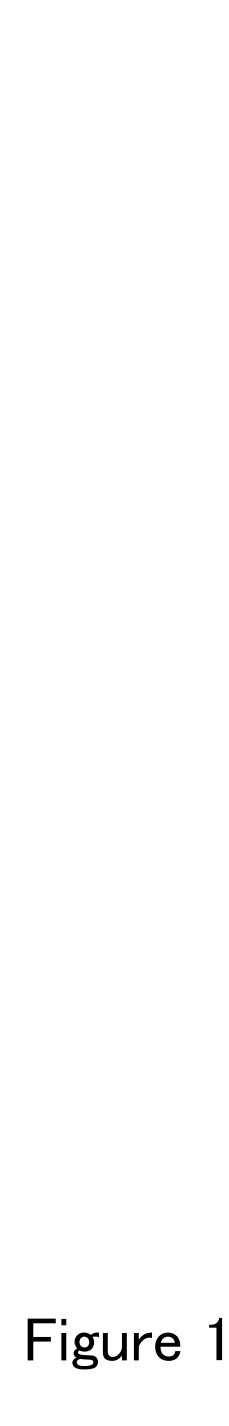




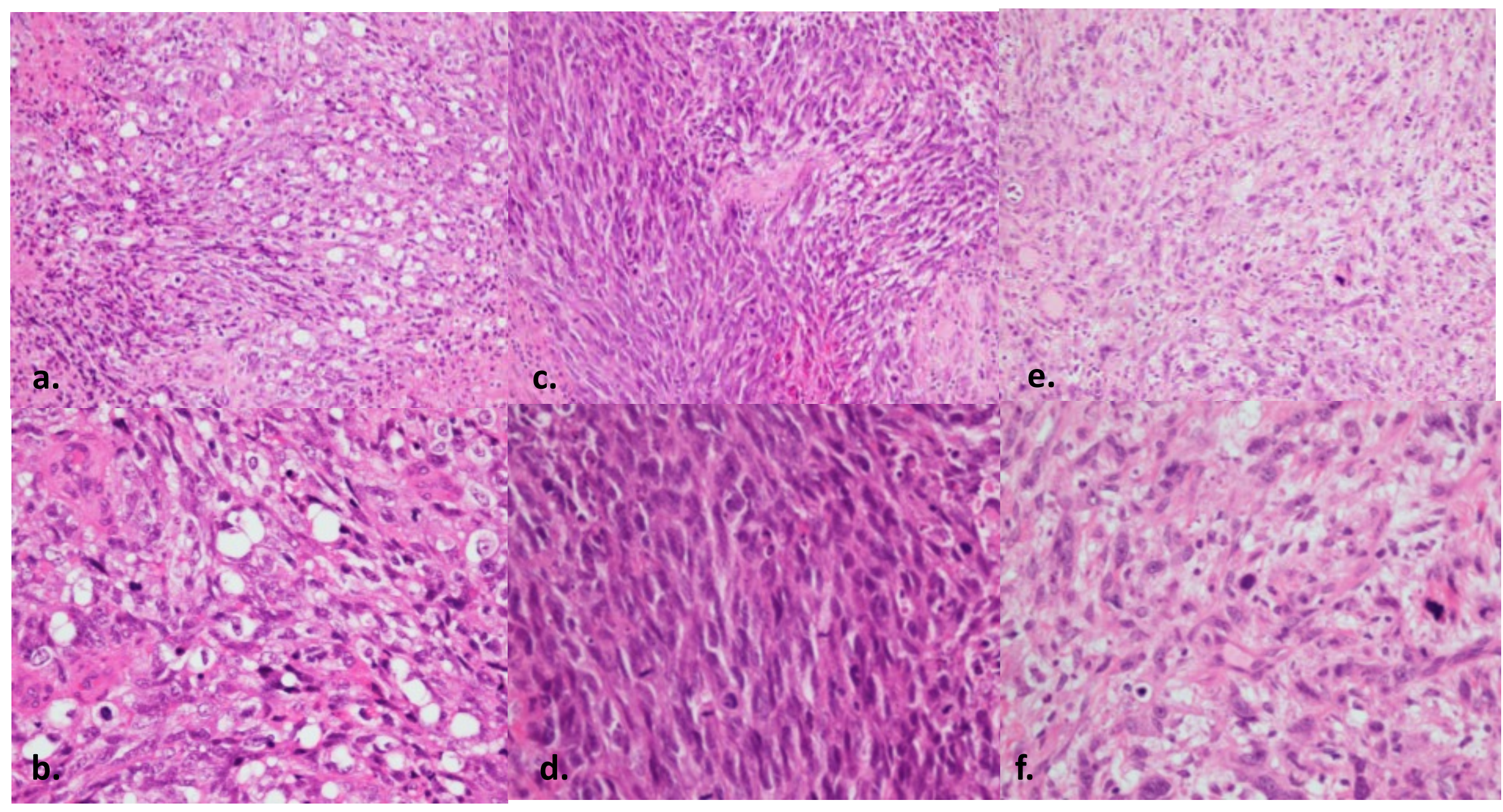

Figure 2 